\title{
LEARNING HOW TO LEARN AND TEACH: MENTOR AND MENTEE TEAM
}

Dr. Vishwas Narayan Bedekar, University of Arkansas

Dr. Vishwas N. Bedekar is currently a Research Assistant Professor in the Department of Mechanical Engineering at the University of Arkansas under the mentoring of Prof. Ajay P. Malshe since January 2011. Dr. Bedekar holds a Ph.D. degree in Materials Science and Engineering with emphasis on "Design of novel sensor architectures combined with energy harvesting techniques", Masters and Bachelor's degree both in Mechanical Engineering. He has several (6+) years of experience in synthesis and characterization of ceramic/piezoelectric materials and carbon nanotube based magnetic/piezoelectric nanomaterials. He is being mentored by Prof. Malshe under Teaching Experience for Research Faculty program.

\section{Mr. John Lee, University of Arkansas}

John Lee is a doctoral candidate at the University of Arkansas. He graduated from Oklahoma Christian University in 2008 with a BSME.

Dr. Douglas E. Spearot, University of Arkansas 


\title{
LEARNING HOW TO LEARN AND TEACH: MENTOR AND MENTEE TEAM
}

\author{
Vishwas N. Bedekar, John Lee, Douglas E. Spearot, Ajay P. Malshe* \\ Department of Mechanical Engineering, University of Arkansas, Fayetteville, AR
}

*Contact Author Information- Tel (479) 575-6561; Email apm2@uark.edu

\begin{abstract}
Many Ph.D. students take a semester-long Professoriate or Teaching Practicum course as part of their doctoral coursework, yet most courses of this type do not provide the student or postdoc a significant opportunity to develop and refine their skills as a teacher in the classroom. The objective of the Teaching Scholars pilot program in the Department of Mechanical Engineering at the University of Arkansas was to train a postdoctoral researcher and a graduate student on pedagogical techniques, developing effective lectures, course management and organization, and timely delivery of subject related material such as class notes, grades, homework, tests, etc. using MEEG 2303: Introduction to Materials as a learning vehicle. Common pedagogical techniques included communication and presentation skills, body language and tonal variation for engagement, preparation of information rich slides and explanation which helped the graduate student and postdoc provide a spherical learning experience for students. In this pilot program, the mentees learnt five key aspects of modern teaching: (1) dedication and empathy towards students, (2) engaging and exciting the students in the class for the subject matter and selfmotivated learning after-class, (3) giving and receiving constructive feedback, (4) learning how to learn and teach, and (5) connecting the dots between classroom learning and real world applications. We assessed this program informally during tests, projects, and an industry visit during the first semester, and then formally via an online evaluation in the second semester of the program. This manuscript presents the outcome of the teaching mentorship experiment. Our approach could provide a pathway for new engineering faculty to become effective teachers and successful mentors.
\end{abstract}

\section{Introduction and Background}

The $2 \mathrm{l}^{\text {st }}$ century has seen a significant shift from bricks to clicks, from simultaneous to nonsimultaneous engineering and communication cultures. ${ }^{1-2}$ Traditional classrooms, in the walls of bricks, have transformed with integration of software and design tools, digital demonstrations, and other visual tools, into the next generation of classrooms. In this modern teaching environment, virtual real life experiences could be created to train our students in preparation for workplaces and, at the same time, inspire their thinking of new and novel ideas. This changing, teaching-learning environment also needs effective and simple changes in the modes of pedagogical processes.

Concurrent to the teaching environment evolution there has been a systematic shift from traditional teaching to teaching-research and discovery-based learning styles. This shift is partly inspired by the growing emphasis of educational institutions to increase research revenue and academic prestige, and partly to cater to the next-generation of students whom are exposed to 
instant learning media, such as YouTube, Khan Academy, and others, where novelty offered by research inspires their learning and satisfaction.

The teaching faculty, commonly referred to as professors and instructors, come from different paths of prior experience, which includes fresh postdoctoral fellows, where research is a priority, fresh doctoral graduates, where research is a priority, industrial practitioners, who practice engineering for solving real-life problems, and professors, including those who have been away from research for more than a few years to a decade. Though they have common goals, their skill sets vary. Out of this set, a notable population of young professors and instructors are and will be fresh postdoctoral research associates, as well as fresh doctoral graduates.

This particular section of the teaching and instructor community is likely to have the longest teaching careers, but at the onset of their careers they will have the least teaching and hands-on experience. As fresh instructors, they will have limited experience with new pedagogical techniques which will empower learning in a hybrid brick-click classroom. ${ }^{3-4}$ Recently, in the Department of Mechanical Engineering at the University of Arkansas, an experiment was conducted, titled Teaching Scholars program, to develop a conscious approach for training a postdoctoral research associate and a doctoral student, under the guidance of two professors, who started their careers as a fresh postdoctoral research associate and a fresh doctoral graduate. This manuscript discusses the approach, the model, and the current findings of this pilot program from the perspective of each of the participants.

\section{Technical/Teaching Training Scope and Approach}

\section{A. First Semester Training - Building Mentor-Mentee Relationship and Learning Pedagogy}

In the spring of 2012, as mentees, Dr. Bedekar (a postdoctoral fellow) and Mr. Lee (a doctoral graduate student) were paired with Prof. Malshe in MEEG 2303: Introduction to Materials Science and Engineering. This experiment was supported by the Department of Mechanical Engineering and part of the motivation came through Prof. Malshe's involvement in a National Science Foundation (NSF) funded project. MEEG 2303 class had approximately 50 students from Mechanical Engineering and Industrial Engineering. Class was scheduled to be taught twice a week, with each class scheduled for one hour and twenty minutes. Variation in seniority of students in the class created a diverse teaching environment because of the varying degrees in students' previous preparation. Fundamentals of physics, chemistry and math were technical prerequisites for this class.

Prof. Malshe met with both mentees a few weeks in advance for "team-building." For this unique experiment, establishing a well thought out and trusting relationship between mentor and mentee was key to achieve depth of training. Initial and all proceeding meetings involved mentor and mentees sharing technical backgrounds, and motivations to participate and seek experience from this experiment. Also the mentor-mentee team discussed mentees' career goals for the next five years and expected importance of this experience. Establishment of technical and personal expectations early in the process and managing those expectations in the form of milestones were vital for achieving a sense of accomplishment and positive motivation for the mentees. 
MEEG 2303 applied four modes of learning. The first mode included learning through multimedia including PowerPoint slides, subject related movie clips, displays of recent discoveries in the subject and stimulating stories of industrial experiences for applications of materials and manufacturing. The second learning mode included learning problem-solving skills through classroom exercises and one-on-one assistance during drill sessions. The third mode of learning was unique in a class-wide project, “Adopt-A-Material,” where each student adopted an engineering material (similarly, like adopting-a-pet) based upon their interest, major and previous exposure to various materials. During the semester, each student acquired the material (e.g. copper wire for copper), and researched and developed a display poster discussing structure/bonding, processing techniques, product application and companies that produce and use the material. At the end of the semester there was "Adopt-A-Material” poster day where students presented their posters and were evaluated with external judges. The fourth mode of learning was through a visit to a materials manufacturing company, Kennametal, where students saw materials such as tungsten carbide and cobalt. The students were also able to observe the manufacturing processes necessary to create the tungsten carbide-cobalt composite, methods for testing the composite, and their applications for the gas-oil industry. Mentees worked with Prof. Malshe in planning, development and execution through the application of the above four modes of learning and teaching. In this process of learning and teaching, mentees learnt pedagogical techniques for "curiosity" driven learning, class management process, grading system and special considerations, and during this process developed a caring attitude for students. During the semester, mentees had systematically created opportunities to experiment and refine pedagogical techniques in the classroom and plenty of opportunities to interact with students. Mentees were evaluated periodically and the feedback was provided in informal settings for continuous improvements and positive motivation.

\section{B. Second Semester Training - Pedagogy Refinement and Course Management}

In the second semester of the Teaching Scholars program, Mr. John Lee was paired with Prof. Spearot to teach MEEG 2303: Introduction to Materials. This decision allowed Mr. John Lee to refine the notes that he generated during his first semester working with Prof. Malshe and exposed him to different viewpoints on pedagogical techniques and course management providing him with a more broad experience. Further, the composition of MEEG 2303 during the fall 2012 semester was very different than that in the spring 2012 semester. At the beginning of the semester, MEEG 2303 had an enrollment of 175 students with the majority of the students ( $>$ 85\%) being sophomore mechanical engineering majors. The balance of the students were industrial engineering majors who can take this class as a technical elective in their curriculum. In addition, MEEG 2303 during the fall 2012 semester was scheduled 3 times per week (Monday, Wednesday, Friday) for 50 minutes providing Mr. Lee with the experience of teaching more frequently in shorter segments than during the spring 2012 semester.

During the summer, Mr. Lee provided Prof. Spearot with a complete overview of the pedagogical techniques he discussed with Prof. Malshe and the training methods that Prof. Malshe employed with Mr. Lee and Dr. Bedekar. Using this information, Mr. Lee and Prof. Spearot generated a plan to provide him with a complementary experience, which does not duplicate the training that the he received from Prof. Malshe. Of particular focus in the second 
semester of the Teaching Scholars program was (1) management in a very large class, (2) syllabus content and (3) balancing teaching and research responsibilities. In addition, Prof. Spearot worked with the Department of Mechanical Engineering staff to develop a formal evaluation survey for Mr. John Lee.

In preparation for the fall 2012 semester, Prof. Spearot involved Mr. Lee in every decision related to the management of the large course, including writing of the course syllabus, decisions related to the weight provided to each assignment and exams in the course, week-by-week planning of course topics and homework problems, and determination of homework and exam dates. Prof. Spearot and Mr. Lee developed a strategy to manage homework submission, homework distribution to the graders, and drill session coverage. Due to the size of the course and the position of the course as one of the first "real" engineering classes that mechanical engineering majors take in their curriculum, Prof. Spearot stressed to Mr. Lee the importance of organization and clarity in the course objectives. For example, the students were provided with a list of reading assignments, homework problems, homework due dates and exam dates on the first day of class as part of the syllabus. This allowed the students to plan ahead and to address any potential conflicts with assignments in their other sophomore level classes.

For the first month of the semester, Mr. Lee attended every class and observed Prof. Spearot's lecture style, including his use of PowerPoint and the white board and his approach to interact with students in a large lecture hall. After each lecture Mr. Lee and Prof. Spearot discussed which topics appeared to resonate well with the students and what methods Prof. Spearot used to entice class interaction and questions. At the end of the first month, Mr. Lee began to develop and deliver his own lectures with Prof. Spearot in attendance. This process began with Mr. Lee giving 1 lecture per week for a three week period. Several days prior to his lectures, Prof. Spearot reviewed Mr. Lee's PowerPoint slides and his plan for presenting the course material. Prof. Spearot stressed to Mr. Lee that he must develop his own personal lecture style leveraging his discussions with both mentors, his mastery of the course material and his experience as a student in undergraduate courses. After each lecture Mr. Lee and Prof. Spearot spoke about the lecture and Prof. Spearot provided Mr. Lee with a written summary of the strengths and weaknesses of his performance (related to pedagogy and subject mastery).

Of critical importance to new faculty is the ability to balance both teaching and research roles. To provide Mr. Lee with this experience, Mr. Lee delivered 3 lectures per week over the next 1 month period. Mr. Lee's dissertation advisor (Prof. Adam Huang) was notified of this plan and was advised that he should not observe a marked decrease in his research productivity. During this month, Mr. Lee's lectures covered critical topics in Introduction to Materials such as stressstrain diagrams, fracture mechanics and fatigue failure. Prof. Spearot attended each lecture (usually sitting in a different place within the lecture hall to gauge PowerPoint slide readability and lecture audibility). Again, after each lecture Mr. Lee and Prof. Spearot spoke about the lecture and Prof. Spearot provided Mr. Lee with a written summary of the strengths and weaknesses of his performance. Further, at the culmination of this one month period, an anonymous online course survey was provided to the students in the course which mirrors the actual course survey that is given to the students at the end of each semester. The results of this survey were very positive of Mr. Lee's technical abilities and many students provided constructive feedback related to his use of PowerPoint and his lecture delivery, which will 
undoubtedly allow Mr. Lee to refine his teaching abilities after the completion of his dissertation. Most importantly, the students in the class felt that Mr. Lee showed continuous improvement over the one month period indicating that the training that he received made a positive impact on his lecture abilities and provided him with a solid foundation to build upon once he begins his career in academia.

\section{Learning How To Learn}

\section{A. Mentee: Postdoctoral Research Associate}

\section{Motivation For Learning}

One of the key aspects of a successful doctoral graduate is the ability to conduct fundamental scientific research independently and interdependently. A fresh Ph.D. graduate has a lot of hands-on experience in research and experiments or simulations; however, a fresh graduate has very little exposure to the fundamentals of teaching. To become a successful tenure-track faculty, a new professor needs to provide excellent teaching, groundbreaking research and outstanding service to the department/university. Through Ph.D. level research the candidate learns to be a successful researcher by building laboratory experiments, performing simulations and publishing articles in top-notch journals. An aspiring tenure track faculty candidate has the right motivation to provide outstanding service to the university by serving on thesis committees, taking active part in faculty meetings, bringing in new ideas and suggesting new courses based upon their previous research expertise. However, this is not enough to become a successful teacher at a university. One has to go through a rigorous teaching training to understand the various aspects of modern teaching. A postdoctoral candidate is on a fast-track gaining teaching experience, understanding the students, being empathetic to students and learning to provide the best teaching environment. The postdoc is highly motivated to take the extra responsibility of managing the course such as setting up the homework and tests, grading the homework and tests, tracking the performance of each student throughout the semester and helping them in various ways to making learning process more interactive and productive. Hence, the motivation of a postdoctoral associate along with related baseline preparations are relatively different than a graduate student learning to teach.

Dr. Bedekar expressed his deep interests and his drive to learn the basics of modern teaching to Prof. Malshe at the beginning of the fall semester in 2011, and he was therefore selected as a mentee to teach a graduate-undergraduate combined course in Physical Metallurgy in the fall of 2011 and then the undergraduate level course Introduction to Materials in spring of 2012 as part of the pilot Teaching Scholars program. Dr. Bedekar wants to pursue a career to become a successful tenure-track faculty at a university and hence this pilot program provided him an excellent opportunity to learn how to teach and gain vital firsthand experience in teaching and class management. Prof. Malshe highly encouraged Dr. Bedekar and involved him actively in learning pedagogical techniques and course management and organization.

2. Steps from Pedagogical techniques and Course Management 
Figure 1 shows various resources used for modern teaching and learning experience in a classroom including slides/notes, textbook, real world examples, internet and media to learn basic concepts of materials science and to understand its applications in the real world. Prof. Malshe had a kickoff meeting with Dr. Bedekar and Mr. Lee two weeks before the semester began and laid out the course outline and the flow of chapters. Prof. Malshe proposed to teach the chapters to the undergraduate students as follows: materials basic concepts and bonding was to be taught in the first 4-5 lectures followed by chapters on different types of materials such as metals, ceramics, polymers and composites. This helped students connect the dots between the basic materials concepts and its applications based on material properties. Students gave positive verbal feedback to Dr. Bedekar and Mr. Lee at the end of the semester regarding how much they liked and appreciated this pattern. It not only answered one of the common questions in an undergraduate student's mind, "Why am I studying this and where am I going to use this material?" but also enabled students to learn the "end goal” first and then taking the necessary steps to achieve that goal/application.

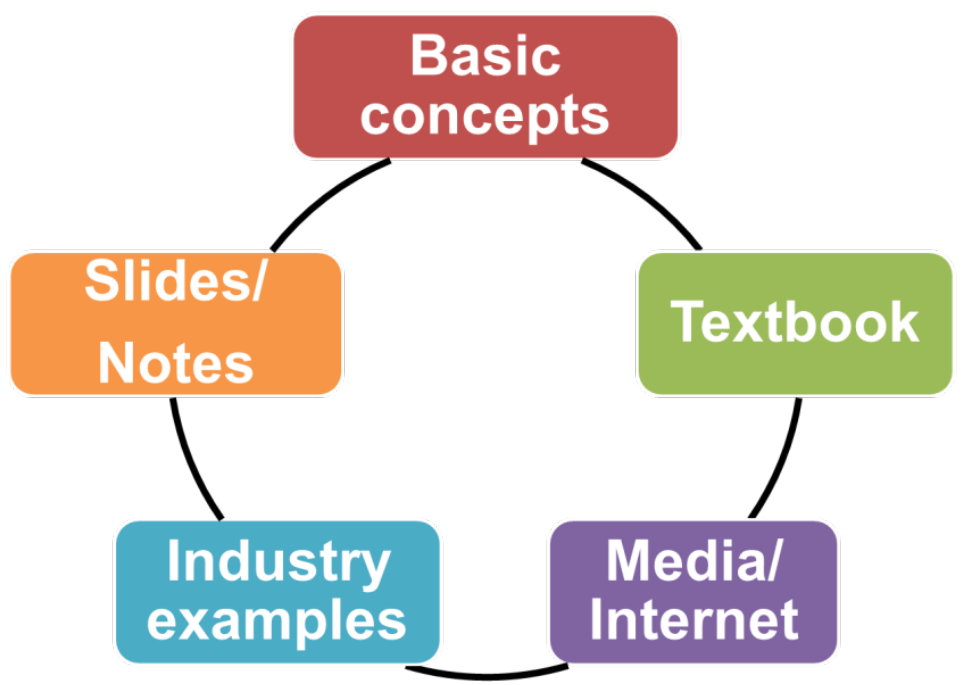

Figure 1: Flowchart of resources used for active learning.

Figure 2 (a) shows the flowchart of necessary steps from pedagogical techniques discussed by Dr. Bedekar and Mr. Lee with Prof. Malshe to learn effective teaching. Prof. Malshe and Dr. Bedekar had regular meetings 1-2 times a week to discuss the various pedagogical techniques for delivering an effective lecture in the class. Prof. Malshe gave Dr. Bedekar a working template of the slides on materials to be taught to the class and Dr. Bedekar worked on the slides to include details such as real world applications, fundamental concepts, and additional slides/information seeking feedback. Prof. Malshe provided prompt feedback on the slides and highlighted the topics/points to be emphasized in the lecture. Dr. Bedekar then practiced the delivery of his lecture independently and interdependently with Prof. Malshe. Both mentees had mock presentation sessions in which Dr. Bedekar learned techniques for engaging the class in meaningful discussion, highlighting the important points, and use of appropriate yet easy to understand technical language. These sessions were highly interactive and immensely helped Dr. Bedekar for independent and team teaching. Team teaching, one of the most effective and innovative experience was introduced by Prof. Malshe to Dr. Bedekar and Mr. Lee. Dr. Bedekar used to deliver lectures to the class and Prof. Malshe would be in the audience listening to the 
material presented and often commented to emphasize or revisit the important topics of that particular chapter. Thus, Dr. Bedekar learned complementary teaching technique. Prof. Malshe gave verbal feedback after each lecture that Dr. Bedekar delivered and made sure that Dr. Bedekar did not repeat lapses, if any. He also provided a written feedback in the middle of semester that included details on voice modulation, body language, enthusiasm and engaging the class at all times. Thus, this pilot program may provide various "to do" steps before one delivers their first lecture. Prof. Malshe emphasized several points in his feedback to Dr. Bedekar that are summarized as follows: (1) Teaching material must be well organized and each slide should have a clear "take-away message". (2) Practice the material multiple times and time the lecture in mock session. (3) Always give a brief 1-2 minute review of information covered in previous lecture to help students' attention and focus. (4) Emphasize topics/concepts/problems that are important from homework HW/exam point of view. (5) Establish clear expectation from students based upon the level of course and the prerequisites. (6) Always tally the points for questions asked in quizzes, HW or exams. (7) Always maintain a positive body language; avoid keeping hands in pockets or folded. (8) Starting with a story or latest news often helps engaging the class in the beginning of the lecture. (9) Walk around while teaching instead of standing at one point and reading the slides. (10) Ask questions to students to get them thinking and synchronized with the flow of lecture. 


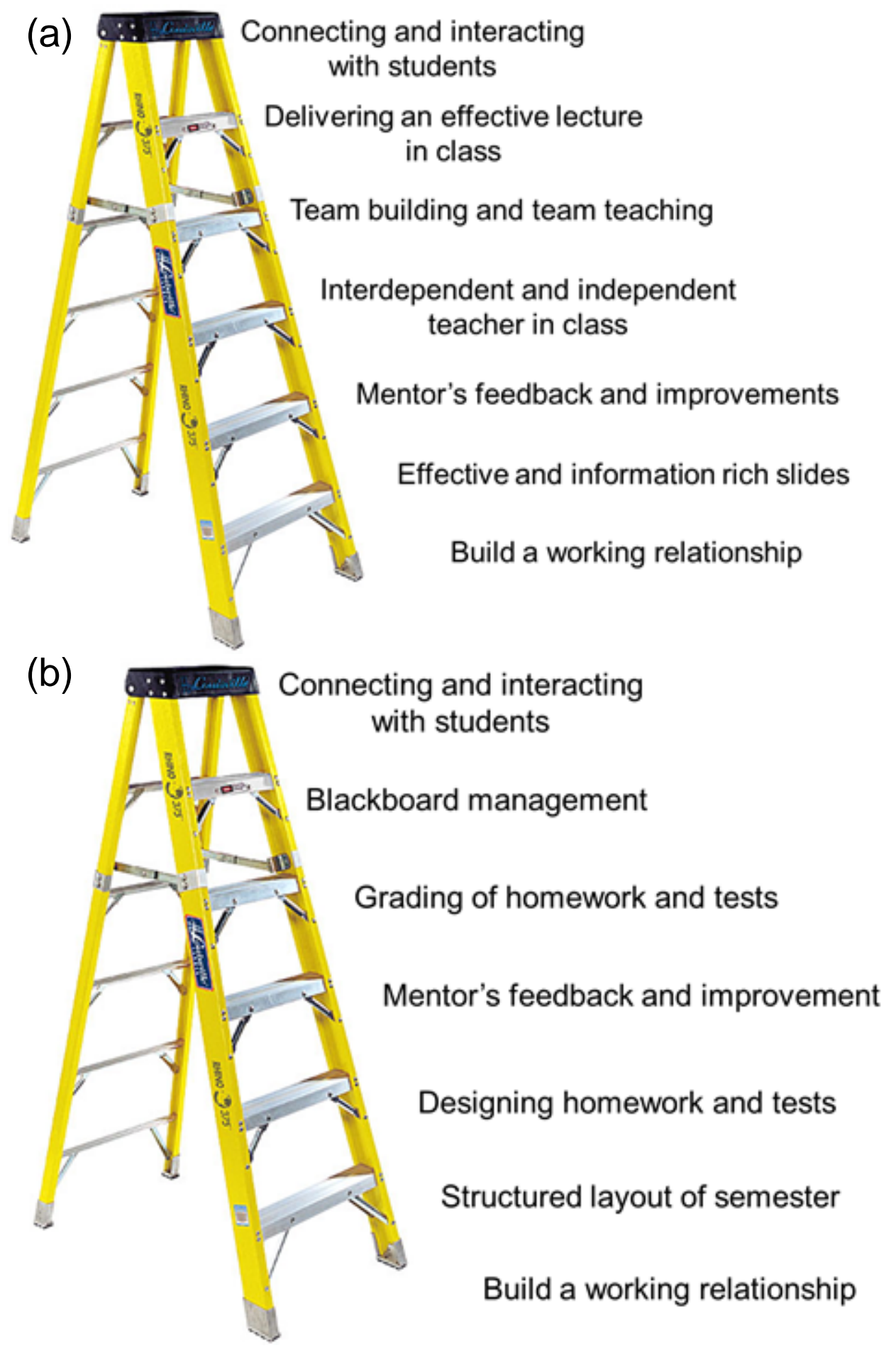

Figure 2: (a) Steps taken towards delivering an effective lecture; (b) steps towards effective course management and organization. ${ }^{5}$

Figure 2 (b) shows the flowchart of necessary steps for course management and organization taken by Dr. Bedekar to learn effective teaching. Dr. Bedekar learned several key features of a successful and effective teacher from Prof. Malshe such as dedication towards students, organizational and management skills, empathy towards students, keeping students involved and 
engaged in class and follow-to-lead mentorship. Prof. Malshe had a systematic plan for implementing the course throughout the semester. He assigned specific lectures to Dr. Bedekar and Mr. Lee so that they could prepare the material ahead of time and receive his feedback for improvement. Dr. Bedekar was actively involved in designing the homework questions following an example set by Prof. Malshe. Meaningful questions that trigger students' curiosity were an important part of the homework. The goal of assigning homework is to test students' knowledge and understanding of the subject while preparing them for the exam. Prof. Malshe and Dr. Bedekar included design type problems in homework so that students became aware of approaching real-world application problems and learned to handle them effectively following the knowledge acquired during the chapter. The model and format of questions from homework was consistent with the exams for this course to avoid any confusion in students' preparation. Dr. Bedekar also participated in grading homework and tests. From this experience, he learned to be fair and consistent in grading several papers. Timely delivery of homework and test results was extremely important for students' self-assessment in the course and becomes easier for the teacher to advise them for improvement in learning. Dr. Bedekar also managed Blackboard for uploading new course announcements, homework assignments, solutions, grades, etc. He learned this effective tool in the modern teaching to communicate with students. There are several builtin tools inside Blackboard such as sending notifications to all users, uploading grades and homework solutions making it highly interactive and user-friendly. It is also one of the best tools to ensure equal opportunity for students to upload their solutions and/or questions to communicate with the instructor.

\section{Learning with Assessment}

Dr. Bedekar actively participated in assessing students in understanding the material, solving homework problems, grading the homework and tests, interacting with students regarding model solutions, and giving prompt feedback for students' overall learning progress in the course. In the undergraduate course MEEG 2303, the teaching team assigned individual projects to the students, named Adopt-A-Material. The projects gave them an opportunity to choose any material/alloy of their interest and asked them to prepare a detailed poster including the history, applications, relevant key engineering properties, manufacturing processes, potential commercial suppliers/users and discuss one application in-depth using structure-property-application relationship. This was followed by a poster presentation session at the end of the semester where students put this information in a poster format and was evaluated by experts testing students' knowledge regarding the material and its applications. This was the first time for an undergraduate class to experience a poster session and it was welcomed by students. Poster session was highly interactive and provided an opportunity to have one-on-one dialogue between the presenter and the visitor. This session helped students learn to effectively communicate their research/results to a targeted audience.

Other than grading and providing feedback to students, Dr. Bedekar also conducted an extra lecture dedicated to problem solving on the chapter "Crystal Structure" which helped several students to solve problems in class and learn ways of efficiently handling the problems in limited amount of time available during the exams. Eighteen out of fifty students in the class attended this extra lecture and were benefitted. Dr. Bedekar received positive verbal feedback from several students regarding the extra efforts taken by him and Prof. Malshe. Also, with dedicated 
office hours along with walk-in help and meeting by appointment for communicating with students for problem solving or assisting on topics from the textbook helped students to work on homework and individual projects in a timely manner. The teaching team's feedback on various junctures in the duration of the course helped several students to self-assess their progress and focus on a particular chapter/topic for understanding in depth.

Dr. Bedekar learned various "things to remember" from his teaching experience working with Prof. Malshe and can be highlighted as follows: (1) that it's not important how much you know as a teacher, but more important is how much students take away (learning and understanding) from the class; (2) being empathetic to students - such as flexibility in scheduling exams in the case of conflicts - students are taking this course at various stages in their undergraduate studies, some as elective or some as a core course; (3) teachers connect the dots between textbook learning and real-world applications to help facilitate efficient and comprehensive learning experience.

\section{B. Mentee: Doctoral Student}

\section{Motivation For Learning}

In the engineering field, skills learned during graduate school are often refined and expanded through a period of internship. Employers understand that employees must undergo a training regimen to become proficient workers. However in academia, new faculty are expected to be effective teachers from the beginning and a transitional period for building needed skills may not be provided. Often an unexpressed, underlying expectation is that one will simply know how to teach from the many examples observed during academic experiences. However, teaching a class is an entirely different situation than just simply sitting in a class and observing. Educators have experienced this transition first hand and understand the discrepancy between academic training and real world application, but generally for engineering a formal program to share these experiences with future generations of instructors is not available to doctoral students. Creating a teaching mentor program at the graduate level is a practical and tremendously helpful method to bridge the gap for engineering students who are interested in pursuing a career in education.

In the spring of 2012, Mr. John Lee was selected to participate in a pilot program for Teaching Scholars at the University of Arkansas. The ultimate goal of this program is to equip graduate students or postdocs with the pedagogical skills necessary to become effective instructors.

\section{Steps from Pedagogical techniques and Management}

Initially, Mr. John Lee was matched with a faculty mentor to advise him throughout the semester. For the program to be successful, the advisor had to be fully invested and committed to dedicating the time necessary for training the graduate student. Prof. Ajay Malshe was involved in planning and teaching the Materials Science and Engineering course and made a formal commitment to mentor Mr. Lee through the process of becoming an engineering instructor. 
As highlighted in previous section, Prof. Malshe (mentor), Dr. Bedekar (mentee), and Mr. Lee (mentee) met regularly to discuss progress with the class. Early in the semester, meetings were held for general course planning and organization but progressed into collaborative efforts for test preparation and interactive feedback on lectures. At the beginning of the semester Mr. Lee was tasked with conducting the drill sessions, where he was able to interact with the students in a more open forum environment. At the University of Arkansas, drill session is a scheduled period during the week when students have the opportunity to ask questions about homework and the course in general. Through his experience with the drills he was able to determine a "to-do" list

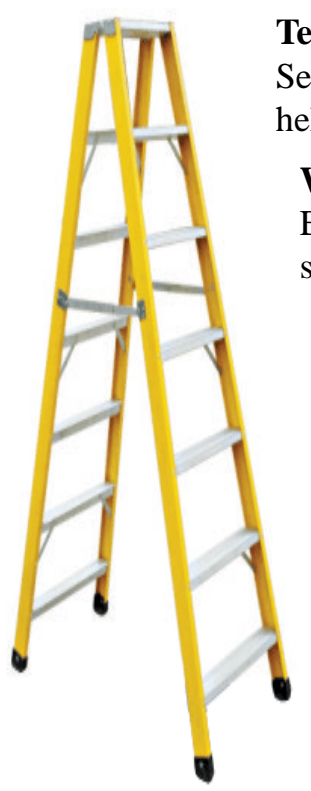

Teacher - Student Relationships

Set office hours and interact with students to help them succeed in class

\section{Writing Exams}

Exams must be carefully crafted to test student's understanding of the course material

\section{Lecture Delivery}

Lectures will not be effective unless the oral delivery skills are honed

\section{Lecture Preparation}

Lectures must be interesting and interactive to engage students

Mentor - Graduate Student Meetings

Regular meetings are necessary for discussion and feedback for interacting with students and answering questions which can be summarized as follows:

Preparation is essential for effective teaching and must be the first thing accomplished to master the material so that an instructor will be ready to help their students. (2) Generally, there are questions over the new material from the classroom environment and these questions must be answered first to reinforce the course objectives or clean-up any misunderstanding to help guide the students learning. (3) An instructor's job is to help the students discover the answers to their own questions, rather than simply giving them the solution to save time and energy. (4) Often Figure 3: Steps towards learning to be an effective instructor while learning students become frustrated and confused and so it is also necessary to motivate a
student to continue the learning process. (5) It is also important to be empathetic to students to develop a trusting relationship which will help foster a learning environment.

Over the course of the semester, Mr. Lee was tasked with delivering six different eighty minutes lectures, predominately utilizing PowerPoint, for a class of approximately 50 students. Before the lectures, Mr. Lee and Prof. Malshe met to discuss the lecture outline and material covered to ensure that it coincided with semester goals outlined in the syllabus. Lectures were edited for flow, clarity, and inclusion of interactive portions to engage the students and reinforce concepts. After each lecture Mr. John Lee received immediate feedback on various aspects of the lecture from delivery to structure. This feedback was essential for Mr. Lee to improve lecture content and for presentation skill development.

During the second semester of the program, fall 2012, Mr. Lee again taught Introduction to Materials (MEEG 2303) but with a different professor, Prof. Douglas Spearot. A new mentor allowed for a fresh perspective and additional feedback, as well as a different teaching style to study. Also, by teaching the same class, Mr. Lee was able to concentrate on improving his lecturing ability while allowing him additional opportunity to refine his original lecture notes for 
the class. The class size for the second semester was 175 students, which was much bigger than the first semester and allowed a unique opportunity to teach a large number of students en masse.

At the beginning of the semester, Prof. Spearot and Mr. Lee outlined the course objectives and created homework assignments. The outlined structure of the class allowed for students to properly prepare for course material to enhance their learning. In addition to providing a clear structure to the overall class, Prof. Spearot emphasized the importance of structuring the individual lectures. Structured lectures are easier to follow for the students as the flow is continuously progressing forward in a logical, organized manner. Mr. Lee also received advice from Prof. Spearot on how to create original lectures when no previous material is provided. Creating structured lectures can be very time consuming, but it is worth the time invested to efficiently convey course material and gain the students' respect.

Mr. Lee's experience with Dr. Spearot during the second semester of the program provided him some important lessons for becoming a successful educator. (1) Creating a well-defined course structure, and following it closely during the semester is beneficial for both the students and the instructor. (2) When writing an exam it is essential to solve every problem of the test to determine length and difficulty . Solving the test prior to distribution minimizes errors and determines if necessary information is missing. (3) Each individual has their own teaching style and it is important to determine that for oneself. (4) It is vital that an instructor be available to the students for consultation because it is key to the students' learning and also helps the instructor determine if there are any holes in students understanding that should be reemphasized later in the semester. (5) For lectures, it is necessary to pre-determine the pace that is required for the material and plan accordingly. Doing so prevents the need to rush material and optimizes student learning. (6) During lectures, vocal volume is important, especially in large auditoriums, and a microphone is not necessarily a bad thing.

\section{Learning with Assessment}

During the first semester Mr. Lee learned from Prof. Malshe that being an instructor means a lifetime dedication to lifelong learning. In addition to reading articles and attending technical seminars to increase knowledge in the engineering field, there must also be a dedication to improving oneself and learning how to constantly become a more effective instructor. So, together Prof. Malshe and Mr. Lee focused on pedagogical techniques, posture, and tonal variations to improve teaching style. Constant feedback throughout the semester from Dr. Malshe prompted improvement in lecture presentation ability and facilitated progression to a more dynamic speaking style. With continued emphasis on improving his lectures, Mr. Lee became more effective at reaching a diverse student population and keeping them engaged during class.

Also, students have a natural desire to learn and Prof. Malshe emphasized that the role of the instructor is to help guide students along the path of enlightenment through a process he termed "connecting the dots". By connecting the dots an instructor breaks down the course material into smaller chunks that are more easily understood and spends the necessary time explaining how various concepts are linked. In doing so, students are able to attain a better overall understanding of the material. 
Working with Prof. Spearot, Mr. John Lee had the opportunity to teach a full four-week section of the class, as well as a few additional lectures spaced throughout the semester. After each lecture Prof. Spearot provided Mr. Lee with written feedback that reinforced the positive aspects of the lecture as well as a constructive critique of areas to improve the lectures. This written documentation was useful for self-reflection and to gauge progressive improvement during the semester. In addition to lecturing over the four week section of the class Mr. Lee was also responsible for designing the exam to test the students' knowledge of key concepts.

Lastly, Prof. Spearot set a terrific example of how to interact with students. For students, it is essential that their professor be available for consultation during the semester. In addition to the standard office hours, Prof. Spearot was available via email, with prompt response. Additionally, a number of drill and tutor times were provided to the students. Mr. Lee interacted with the students during the weekly drill session and was involved in discussions about make-up tests and late homework assignments. Mr. Lee will be able to draw from the experiences and mentor advice over the first two semesters of the Teaching Scholars program when he begins his faculty career.

\section{Conclusions}

In this simple and innovative experiment, the mentee and mentor team has successfully demonstrated a clear approach for the training of graduate students and postdoctoral research associates for effective learning of teaching skills and modern pedagogy. Key features of this program included well thought through program milestones, meaningful engagement between mentor-mentee and empathy for teaching-learning, continuous evaluation and enhancement and strong support at the organizational level (department and college). This program is modular, scalable, and implementable across academic STEM system. This manuscript also describes the specific lessons learned during the pilot program for effective teaching and "things to do" for becoming a successful teacher.

Acknowledgements: Authors especially acknowledge programatic support of Dr. Jim Leylek, Head of the Department of Mechanical Engineering, University of Arkansas, and financial support from the family of Prof. Cecil O. Cogburn for this pilot Teaching Scholars Program. One of the authors (APM) also acknowledges the National Science Foundation (NSF) for partially supporting his effort in participation.

\section{References:}

1. T. L. Friedman, The world is flat, Farrar, Straus \& Giroux, April 2005.

2. N. R. Augustine, Rising Above the Gathering Storm: Energizing and Employing America for a Brighter Economic Future, 2005: The National Academies Press.

3. J. Reisel, "Gaining The Respect Of Your Students: Fundamental Tips For New Engineering Teachers”, ASEE 2010.

4. C. M. Weisbrook and W. Schonberg, "A Streamlined Approach To Developing And Assessing Program Educational Objectives And Program Outcomes”, ASEE 2011.

5. www.ksrsales.com/cat.php?CTGID=51018 


\section{Bibliography}

Dr. Vishwas N. Bedekar

Dr. Bedekar is currently a Research Associate Professor at the University of Arkansas in the Department of Mechanical Engineering. He received his bachelors and masters degrees in Mechanical Engineering in 2002 and 2006, respectively. He received his Ph.D. degree in 2009 from University of Texas at Arlington in the field of Materials Science and Engineering with emphasis on self-powered-sensing under guidance of Prof. Shashank Priya (Virginia Tech). During this time, he was recipient of Dean's Doctoral Fellowship and Graduate Research Assistantship. Dr. Bedekar has published over 30 articles/presentations in international journals, conferences and proceedings including a book chapter. He has been a reviewer on 10 internationally circulated journals and on the editorial board of "Journal of Materials Science Research". He has also been a reviewer and panelist on NSF proposals submitted to the topic of “Smart Materials”. Dr. Bedekar's research expertise and interest has been related to piezoelectric materials and devices, magnetoelectric sensors, energy harvesting, multifunctional nanomaterials, electronic packaging and carbon nanotubes based structures and devices. Dr. Bedekar is currently seeking a full time tenure-track faculty position at a US University.

Mr. John B. Lee

John Lee is a PhD candidate in the Mechanical Engineering Department at the University of Arkansas. His research focuses on fluid vaporization via nanochannel arrays for use in MEMS/NEMS devices. After graduating from Oklahoma Christian in 2008 with a Bachelors of Science in Mechanical Engineering, he was awarded a Doctoral Academy Fellowship at the University of Arkansas, allowing him to pursue a PhD. In 2011 he was selected for a Teaching Scholars pilot program.

Dr. Douglas E. Spearot

Dr. Spearot is an Associate Professor in the Department of Mechanical Engineering and a member of the Institute for Nanoscale Materials Science and Engineering at the University of Arkansas. His research focuses on modeling and simulation of nanoscale material behavior and multiscale structure-property relationships. Dr. Spearot was awarded the 2010 NSF CAREER Award to elucidate the nanoscale mechanisms associated with phase nucleation during vapor deposition and the 2007 Ralph E. Powe Junior Faculty Enhancement Award to study plasticity in nanostructured materials. Dr. Spearot received his B.S. in Mechanical Engineering from the University of Michigan. He completed his M.S. and Ph.D. degrees in Mechanical Engineering from the Georgia Institute of Technology working with Dr. David McDowell and Dr. Karl Jacob.

\section{Dr. Ajay P. Malshe}

Ajay P. Malshe (Ph.D., 1992) is the Distinguished Professor and $21^{\text {st }}$ Century Endowed Chair Professor of Materials, Manufacturing Processes and Integrated Systems at the Department of Mechanical Engineering and adjunct-faculty of Microelectronics and Photonics Graduate Program at the University of Arkansas. Malshe has multidisciplinary research programs in the fields of nanomanufacturing, IC, MEMS and micro and nano device packaging and integration, and surface engineering for advanced machining (mmrl.uark.edu). He has authored over 200 plus peer reviewed publications, 13 books / chapters, and holds 10 patents (4 licensed to industries). He has graduated more than 40 graduate students ( $\mathrm{PhD} / \mathrm{MS}$ ), trained numerous (18) post-doctoral fellows, and provided research experience to several undergraduate (24) and high school students (8) and 6 school teachers, and 5 corporate engineers. His graduates are leaders at key organizations, such as IBM at Almaden, University of Florida, Qualcomm Technology, Texas Instruments, etc. He has received 34 awards/recognitions, including Fellow of American Society of Materials (ASM), Fellow of American Society of Mechanical Engineering (ASME), Fellow of the Institute of Physics (InstP), London, UK, Frost and Sullivan Technology Excellence Award and others. He has an extensive track record of global collaborations with academic institutions and companies from Australia, Japan, India, Germany, Ireland, etc. He is a member of professional societies such as ASEE, ASME, CIRP, ASM, SME, IEEE, MRS and IMAPS, and has arranged and chaired sessions and symposia in the areas of his expertise. He is also the Founder and CTO of NanoMech Corporation (www.nanomech.com), and promotes entrepreneurship and curiosity-based learning. 